Original article

\title{
Efficacy of prototype endodontic obturators for novel root canal obturation techniques using a resin-based sealer in various powder-liquid ratios
} \author{
Yurika Toyama ${ }^{1)}$, Takayuki Yoneyama ${ }^{2,3)}$, and Osamu Takeichi ${ }^{1,4)}$ \\ 1) Department of Endodontics, Nihon University School of Dentistry, Tokyo, Japan \\ ${ }^{2}$ Department of Dental Materials, Nihon University School of Dentistry, Tokyo, Japan \\ ${ }^{3}$ Division of Biomaterials Science, Dental Research Center, Nihon University School of Dentistry, Tokyo, Japan \\ ${ }^{4)}$ Division of Advanced Dental Treatment, Dental Research Center, Nihon University School of Dentistry, Tokyo, Japan
}

Akiko Takatsuki-Hira ${ }^{1}$, Masahiro Kaketani ${ }^{2,3)}$, Kohei Shimizu ${ }^{1,4)}$, Takahito Tamura ${ }^{1)}$, Takeshi Nakamura ${ }^{1)}$,

\begin{abstract}
Purpose: This study aimed to examine novel techniques using prototype endodontic obturators to obturate a resin-based sealer.

Methods: Powder-liquid ratios of MetaSEAL Soft were changed to obtain suitable root canal sealing, and the physical properties for various powderliquid ratios were analyzed according to ISO-6876. Tensile bond strength was also examined. Prototype endodontic obturators with a combination of thread numbers and pitch angles were analyzed for sealing ability after MetaSEAL Soft was obturated in simulated root canals.

Results: Powder-liquid ratios of 1.0:1, 1.1:1, 1.2:1, and 1.3:1 showed suitable physical properties; however, flow for 1.4:1 was below a standard value. Tensile bond strength increased gradually when the powder-liquid ratio changed from $1.0: 1$ to $1.3: 1$, and $1.3: 1$ and $1.4: 1$ showed the highest and lowest bond strengths, respectively. Sealing ability increased when pitch angles of the obturators were $5^{\circ}, 8^{\circ}$, and $11^{\circ} ; 11^{\circ}$ showed the best results. Similarly, sealing ability increased when the thread number was 12,17 , and 22 pitches; 22 showed the best results.

Conclusion: These findings suggest that the prototype endodontic obturator can be useful for obturating MetaSEAL Soft, and a powder-liquid ratio of 1.3:1 MetaSEAL Soft may be the most suitable for achieving excellent sealing.
\end{abstract}

Keywords; physical property test, prototype endodontic obturators, resin sealers, root canal obturation, sealing ability, tensile bond strength

\section{Introduction}

Root canal obturation, the final step in root canal treatment, is usually performed with a core material and a root canal sealer [1]. The purpose of the technique is to avoid microleakage of microbes into periapical periodontal tissue through the root canal or to entomb microbial residue [2,3]. Coronal leakage results in treatment failure [4,5] and retreatment, which is unfavorable for patients and dentists. Thus, root canal obturation is one of the most important parts of the root canal procedure.

There are various techniques for obturating a root canal, including cold lateral condensation, warm vertical condensation, continuous wave, core carrier, and single cone [6]. Each technique provides good sealing ability; however, cold lateral condensation requires more accessory points, and it is difficult to obturate internal root resorption and complicated root canal systems such as isthmuses and fins [7,8]. Warm vertical condensation and thermoplasticised condensation may cause vertical root fracture, increased temperatures on the root surface, and risk for the extrusion of material beyond the apex [9-11]. Disadvantages of single cone techniques have

Correspondence to Dr. Osamu Takeichi, Department of Endodontics, Nihon University School of Dentistry, 1-8-13 Kanda-Surugadai, Chiyoda-ku, Tokyo 101-8310, Japan

Fax: 81-3-3219-8348 E-mail: takeichi.osamu@nihon-u.ac.jp

J-STAGE Advance Publication: February 17, 2021

Color figures can be viewed in the online issue at J-STAGE.

doi.org/10.2334/josnusd.20-0543

DN/JST.JSTAGE/josnusd/20-0543 also been reported [12]. In addition, these root canal obturation techniques require the use of a core material [13]; however, in most cases, excess core materials must be removed to build up core abutment [14]. Thus, more precise, economical, and simpler root canal obturation techniques are preferred.

In this study, the sealing ability of a novel technique was examined, and endodontic obturators were used to seal materials into the root canal without the use of core materials. Prototype obturators were designed and manufactured to achieve more simplified and economical root canal obturation. A resin-based sealer was used to seal the root canal. Root canal sealer is essential to achieve a tight seal and can be used as a lubricant during root canal obturation. Materials used as root canal sealers include zinc oxide-eugenol, non-eugenol, calcium hydroxide, glass ionomer, resin, silicone, and bioceramic [6]. Biocompatibility, radiopacity, and color stability are desirable properties of the sealer [15-17]. In addition, low solubility is important to avoid dissolution by tissue fluids [18]

In this study, MetaSEAL Soft (Sun Medical, Moriyama, Japan), a resin-based sealer, was used to obturate root canals using prototype endodontic obturators. The MetaSEAL Soft was newly manufactured, and the composition was different from MetaSEAL (Parkell, Edgewood, NY, USA), as shown in Table 1. MetaSEAL soft is a dual-curable methacrylate resin-based sealer containing self-etch formula and 4-methacryloxyethyl trimellitate anhydride (4-META), an adhesive monomer, which allows for the formation of a hybrid layer and firm adherence to root dentin [19]. In addition, MetaSEAL Soft does not contain zirconium oxide which makes the material very hard, and is a soft material that can be easily removed with reamers or files during retreatment.

Excellent flow is required when using root canal sealer as a lubricant to allow a seal to form between the root canal walls and core materials or between core materials and accessory points [20]. However, it remains unclear whether powder-liquid ratio recommended by manufactures is preferable for root canal obturation performed without core materials. Thus, the powder-liquid ration of MetaSEAL Soft was changed to find proper root canal sealing in this study. The purpose of this study was to determine the sealing ability of prototype endodontic obturators, and examined the physical properties of MetaSEAL Soft after the change in the powder-liquid ratio.

\section{Materials and Methods}

\section{Flow}

Although the manufacturer's instructions indicate that the powder-liquid ratio of MetaSEAL Soft should be $1.0: 1$, it was changed to $1.1: 1,1.2: 1$, $1.3: 1$, and $1.4: 1$. In the following root canal obturation study, these amounts of MetaSEAL Soft were obturated into simulated root canals made of resin block using prototype obturators. Therefore, the flow, film thickness, setting time, and solubility of the various powder-liquid ratios of MetaSEAL Soft were analyzed according to ISO 6876/2012 [21].

MetaSEAL Soft was mixed for $30 \mathrm{~s}$, according to the manufacturer's instructions. Then $0.05 \pm 0.005 \mathrm{~mL}$ sealer was placed on the center of a glass plate $(50 \times 50 \mathrm{~mm}, 4 \mathrm{~mm}$ thick, $20 \mathrm{~g})$. Then $180 \mathrm{~s}$ after the start of mixing, another glass plate was placed on the sealer and a $120 \mathrm{~g}$ weight was put on top. Finally, 10 min after the start of mixing, the minimum and 
Table 1 Composition of MetaSEAL soft and MetaSEAL

\begin{tabular}{ll}
\hline Root canal sealer & Composition \\
\hline MetaSEAL Soft & Liquid: 4-META, HEMA, dimethacrylates, camphorquinone, water \\
& Powder: bismuth carbonate oxide, organic filler, aromatic amine \\
MetaSEAL & Liquid: 4-META, HEMA, dimethacrylates, camphorquinone \\
& Powder: zirconium oxide, amorphous silica, aromatic amine \\
\hline 4-META: 4-methacryloxyethyl trimellitate anhydride, HEMA: 2-hydroxyethyl methacrylate
\end{tabular}

(a) (b)

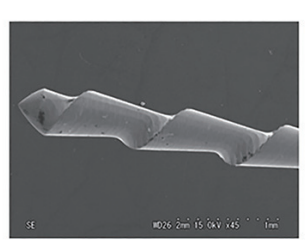

(d)

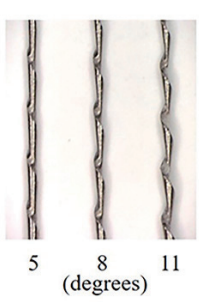

(c)

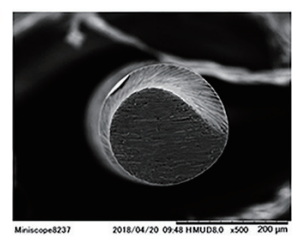

(e)

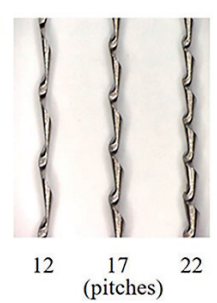

Fig. 1 Configurations of prototype endodontic obturators. (a) A whole image of the obturator. (b-c) Scanning electron microscopic images of the periphery and a cross-section (original magnification $\times 500$ ). (d) The pitch angle was set at $5^{\circ}, 8^{\circ}$, or $11^{\circ}$. (e) The thread number was set at 12,17 , or 22 pitches.

maximum diameters of the compressed sealer were measured with a digital caliper. If the difference between the minimum and maximum diameters was not within $1 \mathrm{~mm}$, the flow test was repeated. The diameter of each sealer was not less than $17 \mathrm{~mm}$.

\section{Film thickness}

A mixed sealer was placed onto a $1.75 \mathrm{~mm}$ thick glass plate with a surface area of approximately $200 \mathrm{~mm}^{2}$, and another glass plate was put on top. Then $180 \mathrm{~s}$ after the start of mixing, a load of $150 \pm 3 \mathrm{~N}$ was applied vertically onto the second glass plate. Then $10 \mathrm{~min}$ after the start of mixing, the thickness of the two glass plates and the sealer was measured with a micrometer (M210-25; Mitsutoyo, Kawasaki, Japan). The difference in the thickness of the plates with and without the sealer was calculated, and the thickness was not more than $50 \mu \mathrm{m}$

\section{Setting time}

A stainless-steel ring mold (internal diameter $=10 \mathrm{~mm}$, height $=2 \mathrm{~mm}$ ) was placed onto a glass plate and filled with a mixed sealer. Then $120 \mathrm{~s}$ after mixing, the mold was placed in a thermostatic chamber at $37^{\circ} \mathrm{C}$ and 95\% humidity. Setting time was determined with a Vicat apparatus (ASTM C266-58T; Marubishi-Kikai, Kobe, Japan), with a flat-end indenter (diameter $=2 \mathrm{~mm}$ ) applying a load of $100 \pm 3 \mathrm{~g}$. The indenter was placed vertically onto the sealer, and the setting time was recorded until it no longer produced an indentation. The setting time was within $110 \%$ of the time suggested by the manufacturer.

\section{Solubility}

A split-ring mold (internal diameter $=20 \mathrm{~mm}$, height $=1.5 \mathrm{~mm}$ ) was placed on a glass plate and filled with a mixed sealer. Another glass plate on a polyethylene film was placed onto the sealer, and the glass plate was carefully removed. The mold was stored in a thermostatic chamber at $37^{\circ} \mathrm{C}$ and $95 \%$ humidity for 50\% longer than the setting time suggested by the manufacturer. The set sealer was removed from the mold and weighed with an analytical balance (Advanced Level Balances XS-205; Mettler-Toledo International, Columbus, OH, USA). Two hardened sealers were placed in a Petri dish (diameter $=90 \mathrm{~mm}$ ), immersed in $50 \mathrm{~mL}$ water, covered, and stored at $37^{\circ} \mathrm{C}$ and $95 \%$ humidity for $24 \mathrm{~h}$. The sealers were then removed and washed with $2-3 \mathrm{~mL}$ water. The water was recovered in the same Petri (a)

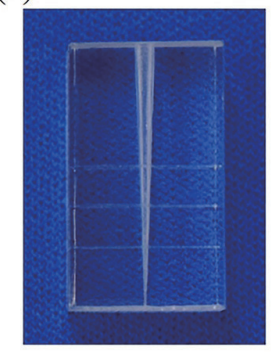

(c)

(b)

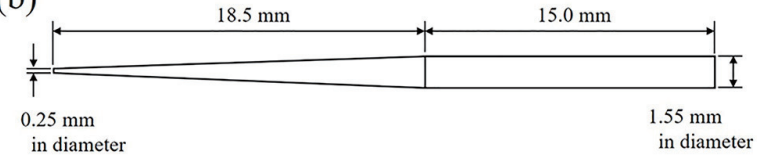

Fig. 2 Equipment for root canal obturation. (a) A resin block as a simulated root canal. (b) A core rod used to simulate a single straight root canal. (c) Apparatus for root canal obturation.

dish and dried at $110^{\circ} \mathrm{C}$, then cooled in a desiccator to room temperature. The original mass of a Petri dish and the desiccated dish were weighed, after which solubility was calculated. The test was performed twice, and the mean percentage was not more than $3 \%$.

\section{Tensile bond strength}

The powder-liquid ratio of MetaSEAL Soft was changed to 1.0:1, 1.1:1, $1.2: 1,1.3: 1$, and 1.4:1, and the bond strength was examined, as follows. Bovine mandibular incisors were prepared as flat dentin surfaces. Briefly, labial surfaces of the coronal part were ground with 220-grit water-resistant abrasive silicone-carbide $(\mathrm{SiC})$ paper (Sankyo Rikagaku, Okegawa, Japan) and water to expose the dentin. The teeth were mounted in self-curing acrylic resin (Tray Resin II; Shofu, Kyoto, Japan) to flatten the dentin surface. The dentin surface was then polished with 600 -grit $\mathrm{SiC}$ paper to standardize the bonding areas. Spacers $(50 \mu \mathrm{m}$ thick; Startraper GP; Sakurai, Tokyo, Japan) with a hole $4 \mathrm{~mm}$ in diameter were put on the polished dentin surfaces, and mixed MetaSEAL Soft (1.0:1, 1.1:1, 1.2:1, $1.3: 1$, or 1.4:1 powder-liquid ratio) was used to fill the hole. Excess root canal sealer was carefully removed with a cement spatula. Cylindrically shaped resin rods made of polymethyl methacrylate $(6 \mathrm{~mm}$ in diameter, 12 $\mathrm{mm}$ long) were placed vertically on the sealer and then loaded with $10 \mathrm{~N}$ for $10 \mathrm{~s}$. The spacers made a precise gap between the dentin and the rods. The specimens were stored in $37^{\circ} \mathrm{C}$ water for $24 \mathrm{~h}$.

Specimens were mounted in a universal testing machine (Instron model 5567; Instron, Norwood, MA, USA). A tensile load was applied to rods at a cross-head speed of $1 \mathrm{~mm}$ per minute. The experiment was repeated six times. The force $(\mathrm{kPa})$ was recorded, and the bond strength was calculated. Six specimens were used for each powder-liquid ratio.

\section{Configurations of prototype endodontic obturators}

Prototype endodontic obturators (MANI, Utsunomiya, Japan) were machined from stainless steel wire and equipped with a contra-angled handpiece (Fig. 1a). The length of the working area was $16.5 \mathrm{~mm}$ with a 0.02 constant taper. The diameter of the apical tips (D1) was $0.25 \mathrm{~mm}$. The periphery (Fig. 1b) and a cross-section (Fig. 1c) of the obturator are shown. No cutting edges or cutting-guided tips were present. The pitch angle was set at $5^{\circ}, 8^{\circ}$, or $11^{\circ}$ (Fig. 1d) against the axis of the obturators, and the thread number was set at 12, 17, or 22 pitches (Fig. 1e). 
(a)

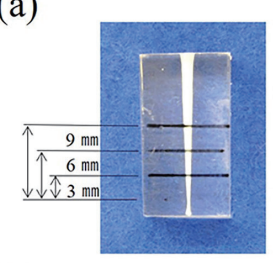

(c)
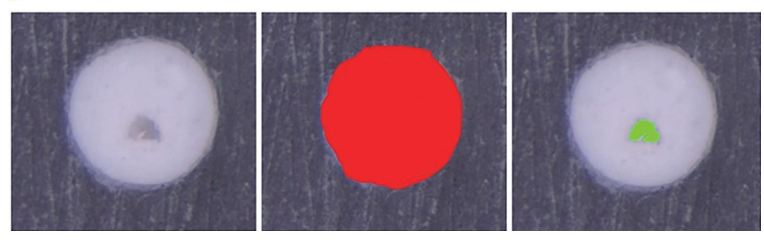

Fig. 3 Test of sealing ability. (a) A simulated root canal obturated with MetaSEAL Soft. (b) An obturated resin block cross-sectioned at the lower, middle, and upper areas with a low-speed saw. (c) Examination of sealing ability with image analysis software; crosssection before examination (left), with red showing an original root canal (middle) and green showing bubbles (right).

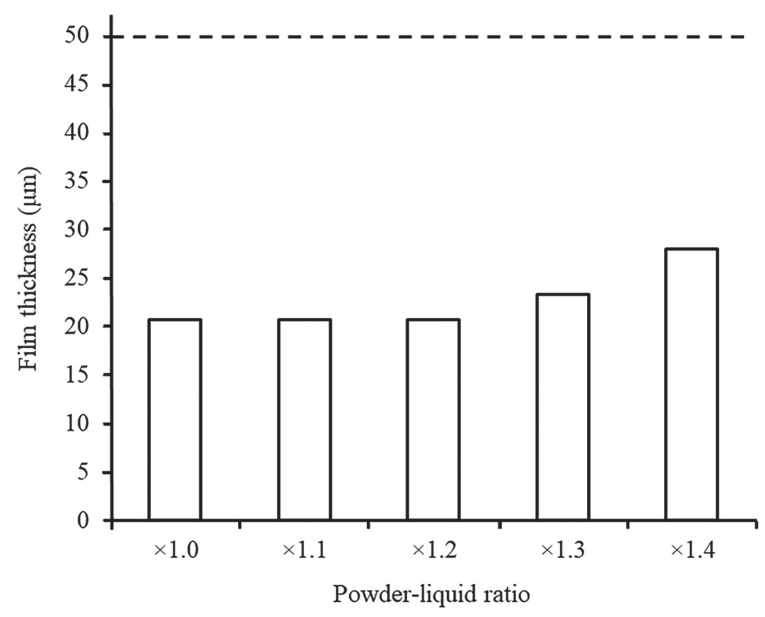

Fig. 5 Film thickness was not greater than $50 \mu \mathrm{m}$, shown by a dotted line.

\section{Resin block for simulated root canals}

Resin block (Fig. 2a; Nisshin Dental Products, Kyoto, Japan) was manufactured using stainless steel wire (MANI) as a core rod to form a simulated single straight root canal. The rod, which had a smooth surface, was 0.25 $\mathrm{mm}$ in diameter with an apical tip with a 0.07 constant taper (Fig. 2b). The resin block had $18.5 \mathrm{~mm}$ of working area with a simulated apical foramen $0.15 \mathrm{~mm}$ in diameter $2.0 \mathrm{~mm}$ beneath the working area.

\section{Root canal obturation}

Resin block was fixed at a perpendicular angle with a vice. A 16:1 contraangled handpiece (ATR Tecnika Vision Motor, Dentsply Maillefer, Tulsa, OK, USA) was fixed to a locking device equipped to move up and down (Fig. 2c). Root canals of resin block were obturated with MetaSEAL Soft with prototype endodontic obturators. A powder-liquid ratio of 1.3:1 MetaSEAL Soft was used. The obturators were manipulated at $500 \mathrm{rpm}$ four times with up-and-down motions, and the amplitudes were $17 \mathrm{~mm}$. Working length (WL) was $17.0 \mathrm{~mm}$, which was $-1.5 \mathrm{~mm}$ from the apex.

\section{Sealing ability of the prototype endodontic obturators}

Properties of the prototype endodontic obturators, such as the pitch angle and the thread number, were varied. Obturators with the following properties were examined for sealing ability: 17 threads with pitch angles of $5^{\circ}, 8^{\circ}$, or $11^{\circ}$; and 12,17 , or 22 threads with pitch angles of $11^{\circ}$. Each experiment was repeated six times. After obturation, the resin block was cross-sectioned in the lower ( $3 \mathrm{~mm}$ from baseline), middle $(6 \mathrm{~mm}$ from baseline), and upper ( $9 \mathrm{~mm}$ from baseline) areas (Fig. 3a, b) with a low-speed saw with a thin diamond disk under continuous water coolant (IsoMet; 11-1180-170; Buehler, Lake Bluff, IL, USA). The surface area was examined with a stereomicroscope and photographed with a ruler.

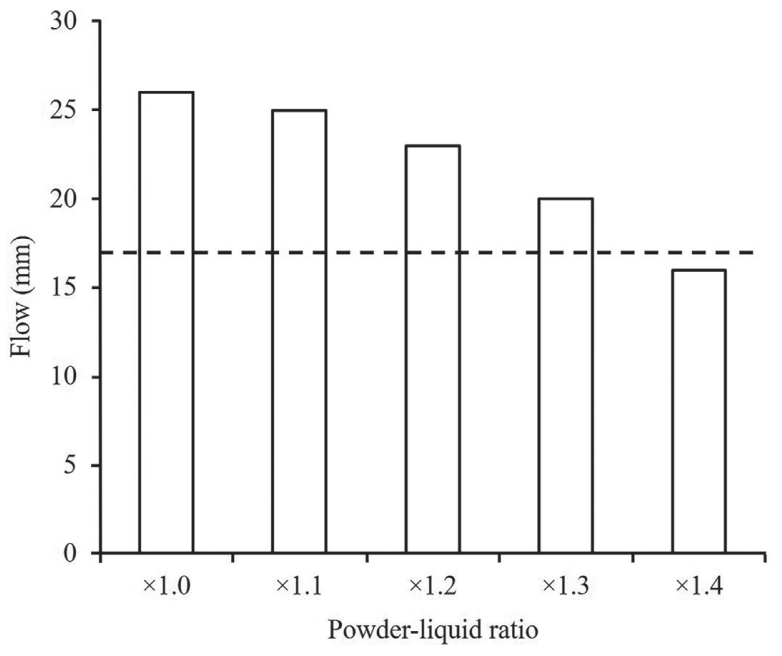

Fig. 4 Flow test; the diameter of the sealer was not less than $17 \mathrm{~mm}$, shown by a dotted line.

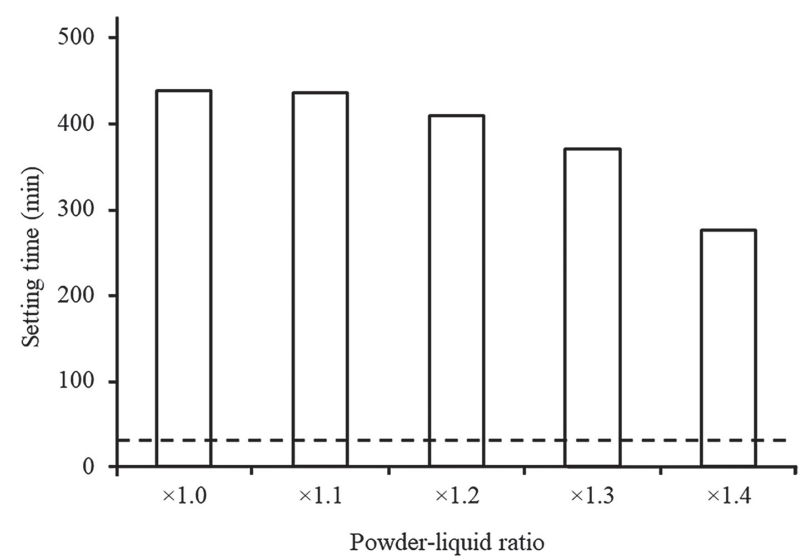

Fig. 6 The setting time was not within $30 \mathrm{~min}$, which is $110 \%$ of the time suggested by the manufacturer, shown by a dotted line.

Photographs were scanned using image analysis software (SigmaScan Pro 5.0; Hulinks, Tokyo, Japan; Fig. 3c), and the areas before obturation and bubbled areas after obturation were calculated as $\mathrm{mm}^{2}$.

\section{Statistical analyses}

Tensile bond strength data were analyzed primarily by Shapiro-Wilk test. Shapiro-Wilk test revealed that tensile bond strength data for all groups followed a normal distribution $(P=0.238)$. Brown-Forsythe test for evaluation of the equality of variance was also analyzed for the tensile bond strength data, and the results demonstrated the homoscedasticity $(P=$ $0.330)$. Tensile bond strength data were then subjected to one-way analysis of variance (ANOVA) followed by Tukey's test.

Sealing ability results of obturators were also analyzed, and Wilcoxon signed-rank test was performed for a comparative study between before and after obturation in each obturator, and Kruskal-Wallis test followed by Steel-Dwass test were performed for sealing ability data with various pitch angles and thread numbers. $P<0.05$ was considered to indicate statistical significance.

\section{Results}

Flow

The results of flow tests were $25.8,25.4,22.8,20.1$, and $16.2 \mathrm{~mm}$ for powder-liquid ratios of 1.0:1, 1.1:1, 1.2:1, 1.3:1, and 1.4:1, respectively. The 1.0:1 ratio had the highest flow, and the flow decreased gradually as the powder-liquid ratio changed from 1.1:1 to $1.4: 1$ (Fig. 4). Only 1.4:1 was lower than $17 \mathrm{~mm}$, the required length of the flow test; 1.0:1 to $1.3: 1$ showed desirable flow. 


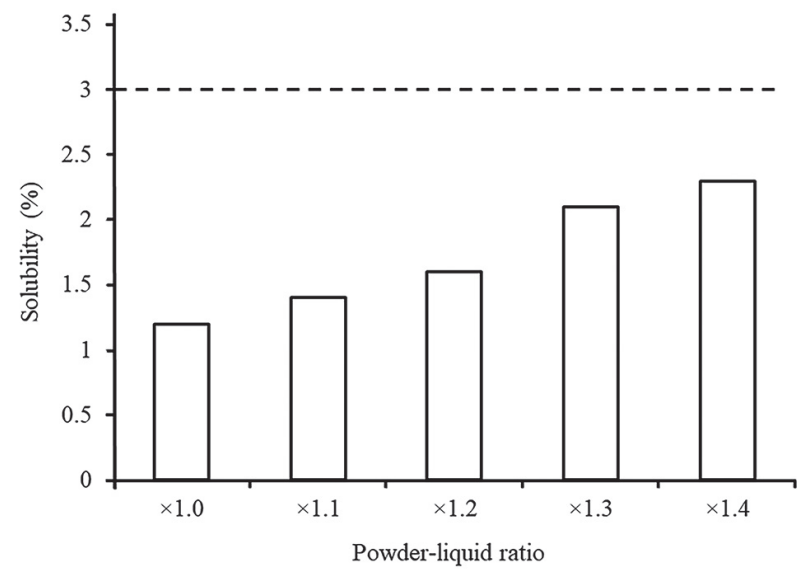

Fig. 7 Solubility was not more than $3 \%$, shown by a dotted line.

(a)
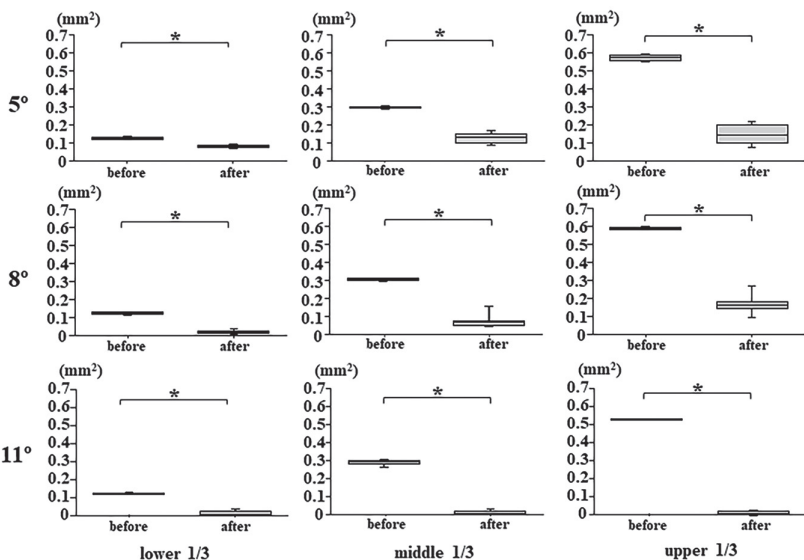

(b)
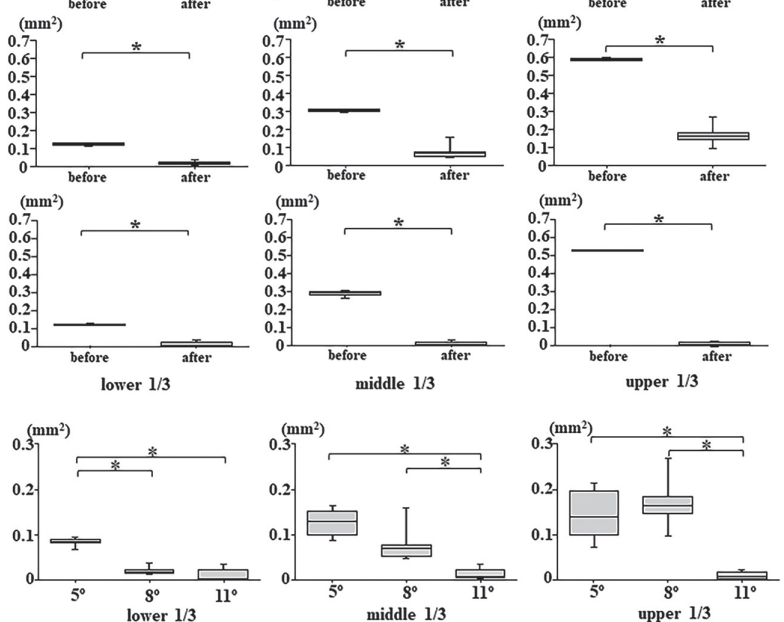

Fig. 9 Sealing ability for obturators with various pitch angles. Tests were repeated six times. Asterisks indicate statistically significant differences between groups $\left({ }^{*} P<0.05\right)$. (a) The areas before obturation and bubbled areas after obturation were compared for each pitch angles at lower, middle, and upper third. (b) Sealing ability using obturators with various pitch angles was compared at lower, middle, and upper third.

\section{Film thickness}

The 1.0:1, 1.1:1, and 1.2:1 ratios had $20.7 \mu \mathrm{m}$ film thickness, and 1.3:1 and 1.4:1 had 23.3 and $28.0 \mu \mathrm{m}$, respectively. Thus, film thickness increased gradually as the powder-liquid ratio increased (Fig. 5). All tested materials were less than $50 \mu \mathrm{m}$ thick, the requirement of the film thickness test.

\section{Setting time}

The 1.0:1 and 1.1:1 ratios had similar results in terms of setting time (438 and $435 \mathrm{~min}$, respectively), whereas 1.2:1, 1.3:1, and 1.4:1 were 408, 370, and $275 \mathrm{~min}$, respectively. Thus, setting time decreased gradually as the powder-liquid ratio increased (Fig. 6). All tested materials were longer than $30 \mathrm{~min}$, the requirement of the setting time test.

\section{Solubility}

The 1.0:1 ratio showed the lowest solubility (1.2\%). As shown in Fig. 7, solubility gradually increased to $1.4 \%, 1.6 \%, 2.1 \%$, and $2.3 \%$ when the powder-liquid ratio changed from 1.1:1 to 1.4:1. All materials had less than $3 \%$ solubility, the requirement of the solubility test.

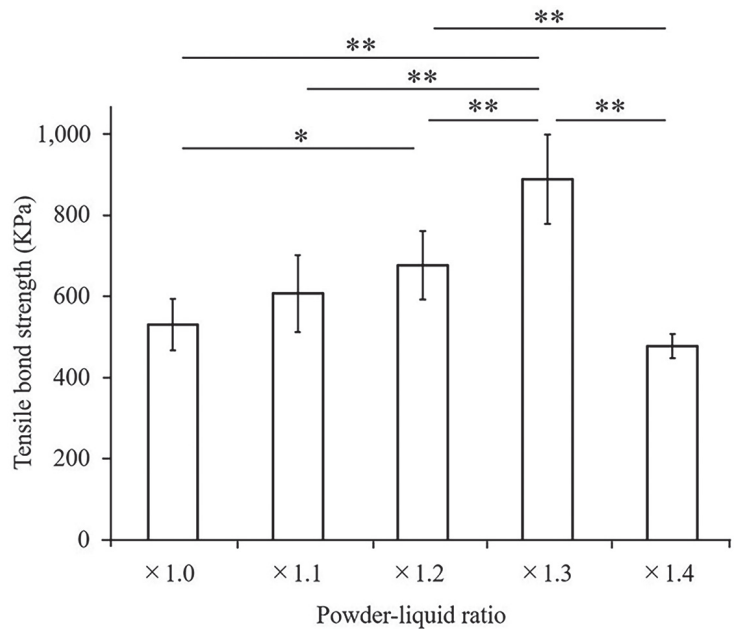

Fig. 8 Tests of tensile bond strength were repeated six times. Asterisks indicate statistically significant differences $\left(* P<0.05,{ }^{*} P<0.01\right)$.

(a)
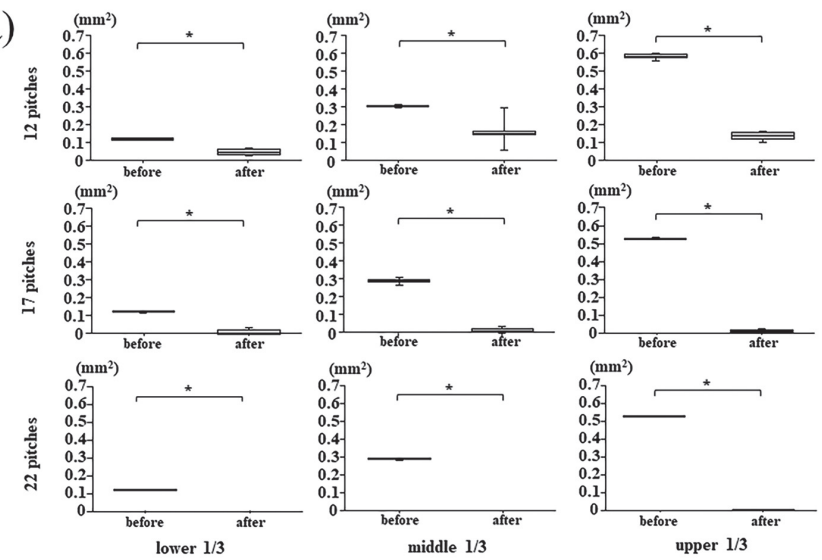

(b)
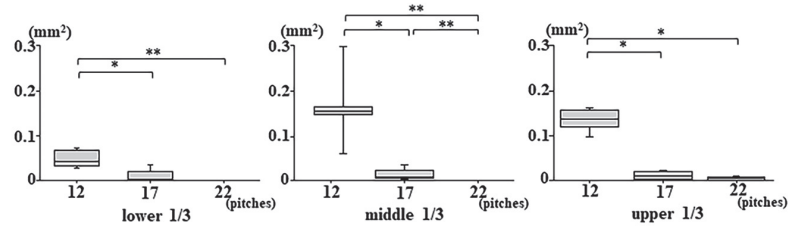

Fig. 10 Sealing ability for obturators with various thread numbers. Tests were repeated six times. Asterisks indicate statistically significant differences between groups $\left({ }^{*} P<0.05, * * P<0.01\right)$. (a) The areas before obturation and bubbled areas after obturation were compared for each thread numbers at lower, middle, and upper third. (b) Sealing ability using obturators with various thread numbers was compared at lower, middle, and upper third.

\section{Tensile bond strength}

As shown in Fig. 8, tensile bond strength increased gradually as the powder-liquid ratio of MetaSEAL Soft changed from 1.0:1 to 1.3:1 (501.0 \pm $91.7,621.0 \pm 91.3,674.0 \pm 75.4$, and $899.7 \pm 102.8 \mathrm{KPa}$, respectively). The 1.3:1 ratio had the highest bond strength, and the difference was significant compared to the other powder-liquid ratios $(P<0.01)$. The 1.4:1 ratio had the lowest strength $(470.5 \pm 32.0 \mathrm{KPa})$.

\section{Sealing ability for various pitch angles of the obturators}

The pitch angles of the obturators were set at $5^{\circ}, 8^{\circ}$, and $11^{\circ}$, and the areas before obturation and bubbled areas after obturation were compared. As shown in Fig. 9a, obturators with $5^{\circ}, 8^{\circ}$, and $11^{\circ}$ pitch angles demonstrated the significant difference between before and after obturation at all areas.

When sealing ability using obturators with various pitch angles was examined (Fig. 9b), statistical analysis demonstrated that $8^{\circ}$ and $11^{\circ}$ pitch angles of the obturators at lower third showed significantly lower bubbled areas than $5^{\circ}$. On the other hand, $11^{\circ}$ showed significantly lower bubbled areas than $5^{\circ}$ and $8^{\circ}$ at middle and upper third. 
Sealing ability for various thread numbers of the obturators

The thread numbers of the obturators were set at 12,17 , or 22 , and the areas before obturation and bubbled areas after obturation were compared. As shown in Fig. 10a, obturators with 12, 17, and 22 pitches demonstrated the significant difference between before and after obturation at all areas.

When sealing ability using obturators with various thread numbers was examined (Fig. 10b), 17 and 22 pitches of the obturators at lower and upper third showed significantly lower bubbled areas than 12 . On the other hand, 22 pitches at middle third showed significantly lower bubbled areas than 12 and 17.

\section{Discussion}

Root canal treatments are commonly performed in dental practices; however, the success rate is far from satisfactory $[22,23]$. Coronal leakage is associated with a recurrence of apical periodontitis [24], and the quality of root canal obturation is important for the success of the root canal treatment [25]. Thus, root canal obturation techniques should be reliable enough to avoid the need for retreatment. In this study, prototype endodontic obturators were used for root canal obturation without core materials such as gutta-percha points. MetaSEAL Soft, a resin-based root canal sealer, was used as a condensation material; the powder-liquid ratio suggested by the manufacturer results in excellent flow, but the sealing ability was not ideal. Therefore, the powder-liquid ratio was changed to improve the sealing ability.

Physical properties tended to decrease as the powder-liquid ratio increased. However, film thickness, setting time, and solubility tests showed that all powder-liquid ratios achieved satisfactory results required by ISO 6876/2012 [21]. Flow tests showed that only the powder-liquid ratio of 1.4:1 did not reach the required level. These results demonstrate that changes in the powder-liquid ratio do not affect most physical properties, except for flow at 1.4:1. Thus, MetaSEAL Soft can be useful for root canal obturation as long as a powder-liquid ratio of 1.0 to $1.3: 1$ is used.

Tests of tensile bond strength indicated that the 1.3:1 ratio had the best bond strength and 1.4:1 the worst. As the powder-liquid ratio increased, the tensile bond strength also increased; however, 1.4:1 may be too high for bond strength. Based on the physical properties and bond strength, a powder-liquid ratio of 1.3:1 of MetaSEAL Soft may be suitable for root canal obturation. Therefore, this powder-liquid ratio was used for the test of sealing ability.

In the preliminary study, a Lentulo spiral or a spiral filler was used for root canal obturation with MetaSEAL Soft because the Lentulo spiral is regularly used for calcium hydroxide dressing in root canals [26]. There was a large bubble in filled materials, and the apical third of root canals was not filled (data not shown). The flow of MetaSEAL Soft, unlike calcium hydroxide paste, may be too low to be filled using the Lentulo spiral, which suggests that the Lentulo spiral cannot be used for the purpose in this study. The prototype endodontic obturator allowed to perform better obturation than the Lentulo spiral and was used to test sealing ability.

Researchers have used several methods to evaluate the sealing ability of the root canal filling materials, such as glucose leakage tests [27], fluid transport methods [28], bacterial leakage tests [29], and dye penetration tests [30]. Image analyses using microcomputed tomography and optical microscopy have also been used for quantitative analyses [31]. In this study, sealing ability was analyzed quantitatively with image analysis software, which is easy and reliable [32]. Changes in the pitch angles and thread numbers of the obturator resulted in different sealing abilities, and the obturator with an $11^{\circ}$ pitch angle and 22 pitches showed the best sealing ability in the apical, middle, and upper third of root canals.

MetaSEAL Soft was used as a condensation material in this study because it is a resin-based sealer with 4-META, which has adhesive properties. It is also soft and can be removed in cases of retreatment. Obturation using the prototype obturator with MetaSEAL Soft showed excellent sealing ability and proper physical properties. The powder-liquid ratio is very important, and the changes made a significant difference in bond strength. A resin-based sealer such as MetaSEAL Soft can be useful in obturation if the powder-liquid ratio is adjusted precisely.

Engine-driven prototype obturators were made from stainless steel wire. The material of the obturators was very rigid, which suggests difficulty of use in curved root canals [33]. A straight root canal of resin block was used in this study. However, many previous reports have suggested that most teeth have canal curvatures [34,35]. Also, $84.3 \%$ of permanent teeth have curved root canals, and $19 \%$ of root canals have more than $27^{\circ}$ curvature [36]. Nickel-titanium (Ni-Ti) instruments, which are very flexible [37], have been recommended for curved root canals [38,39]. Ni-Ti rotary files can follow a curved root canal and shape severely curved root canals [40]. Thus, because most teeth have canal curvatures, obturators made of Ni-Ti alloy should be tested in future studies.

Taken together, it was concluded that the prototype endodontic obturator can be used for root canal obturation with MetaSEAL Soft. A powder-liquid ratio of 1.3:1 MetaSEAL Soft may be the most suitable for achieving excellent sealing ability.

\section{Conflict of interest}

The authors declare no conflict of interest.

\section{References}

1. Kratchman SI (2004) Obturation of the root canal system. Dent Clin North Am 48, 203215

2. Saunders WP, Saunders EM (1994) Coronal leakage as a cause of failure in root-canal therapy: a review. Endod Dent Traumatol 10, 105-108.

3. Engel GT, Goodell GG, McClanahan SB (2005) Sealer penetration and apical microleakage in smear-free dentin after a final rinse with either $70 \%$ isopropyl alcohol or Peridex. J Endod 31, 620-623.

4. Santos J, Tjäderhane L, Ferraz C, Zaia A, Alves M, De Goes M et al. (2010) Long-term sealing ability of resin-based root canal fillings. Int Endod J 43, 455-460.

5. Ricucci D, Siqueira JFJr (2011) Recurrent apical periodontitis and late endodontic treatment failure related to coronal leakage: a case report. J Endod 37, 1171-1175.

6. Tomson RM, Polycarpou N, Tomson PL (2014) Contemporary obturation of the root canal system. Br Dent J 216, 315-322.

7. Oh S, Perinpanayagam H, Kum DJW, Lim SM, Yoo YJ, Chang SW et al. (2016) Evaluation of three obturation techniques in the apical third of mandibular first molar mesial root canals using micro-computed tomography. J Dent Sci 11, 95-102.

8. Olczak K, Pawlicka H (2017) Evaluation of the sealing ability of three obturation techniques using a glucose leakage test. Biomed Res Int, 2704094.

9. Angerame D, De Biasi M, Pecci R, Bedini R, Tommasin E, Marigo L et al. (2012) Analysis of single point and continuous wave of condensation root filling techniques by microcomputed tomography. Ann Ist Super Sanita 48, 35-41.

10. Capar ID, Ertas H, Ok E, Arslan H, Ertas ET (2014) Effects of root canal preparation, various filling techniques and retreatment after filling on vertical root fracture and crack formation. Dent Traumatol 31, 302-307.

11. Wong AW, Zhang S, Li SK, Zhang C, Chu CH (2017) Clinical studies on core-carrier obturation: a systematic review and meta-analysis. BMC Oral Health 17, 167.

12. Iglecias EF, Freire LG, de Miranda Candeiro GT, Dos Santos M, Antoniazzi JH, Gavini G (2017) Presence of voids after continuous wave of condensation and single-cone obturation in mandibular molars: a micro-computed tomography analysis. J Endod 43, 638-642.

13. Li GH, Niu LN, Selem LC, Eid AA, Bergeron BE, Chen JH et al. (2014) Quality of obturation achieved by an endodontic core-carrier system with crosslinked gutta-percha carrier in single-rooted canals. J Dent 42, 1124-1134.

14. Küçükkaya Eren S, Askerbeyli Örs S, Yılmaz Z (2017) Effect of post space preparation on apical obturation quality of teeth obturated with different techniques: a micro-computed tomographic study. J Endod 43, 1152-1156.

15. Markowitz K, Moynihan M, Liu M, Kim S (1992) Biologic properties of eugenol and zinc oxide-eugenol. a clinically oriented review. Oral Surg Oral Med Oral Pathol 73, 729-737.

16. Gatewood RS (2007) Endodontic materials. Dent Clin North Am 51, 695-712.

17. Tour Savadkouhi S, Fazlyab M (2016) Discoloration potential of endodontic sealers: a brief review. Iran Endod J 11, 250-254.

18. Urban K, Neuhaus J, Donnermeyer D, Schäfer E, Dammaschke T (2018) Solubility and pH value of 3 different root canal sealers: a long-term investigation. J Endod 44, 1736-1740.

19. Nakabayashi N, Takarada K (1992) Effect of HEMA on bonding to dentin. Dent Mater 8 , 125-130.

20. Viapiana R, Flumignan DL, Guerreiro-Tanomaru JM, Camilleri J, Tanomaru-Filho M (2014) Physicochemical and mechanical properties of zirconium oxide and niobium oxide modified Portland cement-based experimental endodontic sealers. Int Endod J 47, 437-448.

21. International Standards Organization (2012) Dentistry--Root canal sealing materials. ISO 6876:2012, Geneve.

22. de Chevigny C, Dao TT, Basrani BR, Marquis V, Farzaneh M, Abitbol S et al. (2008) Treatment outcome in endodontics: the Toronto study--phases 3 and 4: orthograde retreatment. J Endod 34, 131-137.

23. de Chevigny C, Dao TT, Basrani BR, Marquis V, Farzaneh M, Abitbol S et al. (2008) Treatment outcome in endodontics: the Toronto study--phase 4: initial treatment. J Endod $34,258-263$.

24. Siqueira JFJr, Rôças IN, Ricucci D, Hülsmann M (2014) Causes and management of posttreatment apical periodontitis. Br Dent J 216, 305-312.

25. Farzaneh M, Abitbol S, Friedman S (2014) Treatment outcome in endodontics: the Toronto study. phases I and II: orthograde retreatment. J Endod 30, 627-633.

26. Teixeira FB, Levin LG, Trope M (2005) Investigation of $\mathrm{pH}$ at different dentinal sites after placement of calcium hydroxide dressing by two methods. Oral Surg Oral Med Oral Pathol Oral Radiol Endod 99, 511-516.

27. El Sayed MA, Taleb AA, Balbahaith MS (2013) Sealing ability of three single-cone obturation systems: an in-vitro glucose leakage study. J Conserv Dent 16, 489-493.

28. Moinzadeh AT, Mirmohammadi H, Hensbergen IA, Wesselink PR, Shemesh H (2015) The correlation between fluid transport and push-out strength in root canals filled with a methacrylate-based filling material. Int Endod J 48, 193-198.

29. Antunes HS, Gominho LF, Andrade-Junior CV, Dessaune-Neto N, Alves FR, Rôças IN et 
al. (2016) Sealing ability of two root-end filling materials in a bacterial nutrient leakage model. Int Endod J 49, 960-965.

30. Ballullaya SV, Vinay V, Thumu J, Devalla S, Bollu IP, Balla S (2017) Stereomicroscopic dye leakage measurement of six different root canal sealers. J Clin Diagn Res 11, ZC65ZC68.

31. Long W, Li J, Liu Y, Jiang H (2019) Effect of obturation technique with immediate and delayed post space preparation on apical voids and bond strength of apical gutta-percha. J Int Med Res 47, 470-480.

32. Gawali PN, Chaugule VB, Panse AM (2016) Comparison of microleakage and penetration depth between hydrophilic and hydrophobic sealants in primary second molar. Int J Clin Pediatr Dent 9, 291-295.

33. Tepel J, Schäfer E, Hoppe W (1995) Root canal instruments for manual use: cutting efficiency and instrumentation of curved canals. Int Endod J 28, 68-76.

34. Willershausen B, Tekyatan H, Kasaj A, Marroquín BB (2006) Roentgenographic in vitro investigation of frequency and location of curvatures in human maxillary premolars. $\mathrm{J}$ Endod 32, 307-311.
35. Lee JK, Ha BH, Choi JH, Heo SM, Perinpanayagam H (2006) Quantitative three-dimensional analysis of root canal curvature in maxillary first molars using micro-computed tomography. J Endod 32, 941-945.

36. Schäfer E, Diez C, Hoppe W, Tepel J (2002) Roentgenographic investigation of frequency and degree of canal curvatures in human permanent teeth. J Endod 28, 211-216.

37. Walia HM, Brantley WA, Gerstein H (1988) An initial investigation of the bending and torsional properties of nitinol root canal files. J Endod 14, 346-351.

38. Capar ID, Ertas H, Ok E, Arslan H, Ertas ET (2014) Comparative study of different novel ickel-titanium rotary systems for root canal preparation in severely curved root canals. J Endod 40, 852-856

39. Pedullà E, Plotino G, Grande NM, Avarotti G, Gambarini G, Rapisarda E et al. (2016) Shaping ability of two nickel-titanium instruments activated by continuous rotation or adaptive motion: a micro-computed tomography study. Clin Oral Investig 20, 2227-2233.

40. Bürklein S, Benten S, Schäfer E (2013) Shaping ability of different single-file systems in severely curved root canals of extracted teeth. Int Endod J 46, 590-597. 